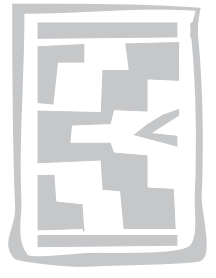

\title{
Comparative histopathology of the lymph nodes, spleen, liver and kidney in experimental ovine trypanosomosis
}

\author{
S.O. OMOTAINSE ${ }^{1 *}$ and V.O. ANOSA²
}

\begin{abstract}
OMOTAINSE, S.O. \& ANOSA, V.O. 2009. Comparative histopathology of the lymph nodes, spleen, liver and kidney in experimental ovine trypanosomosis. Onderstepoort Journal of Veterinary Research, 76:377-383

The infection of Yankassa rams with three important trypanosome species affecting livestock, namely, Trypanosoma congolense, T. vivax and T. brucei produced both acute and chronic fatal conditions. Chronic infections were induced in the three infections by the application of subcurative doses of diaminazene aceturate (Bereni $\left.{ }^{\circledR}\right)$. Pathological changes in the infected animals included splenomegaly and hepatomegaly which were more pronounced in acute than in chronic $T$. congolense infection. However, these changes were more severe in chronic than in acute $T$. vivax infection. While splenomegaly was more pronounced in chronic $T$. brucei infection than in acute, hepatomegaly and lymphadenopathy were more severe in acute than in the chronic condition. The increases in size of the spleen, lymph nodes and liver were associated with congestion, increases in cell density related to increased immunological reactions in the spleen and lymph nodes as well as increase in numbers, size and activity of the phagocytic cells in these organs.
\end{abstract}

Keywords: Comparative pathology, experimental trypanosomosis, ovine

\section{INTRODUCTION}

Trypanosomosis is one of the most devastating and widespread diseases of African livestock. It is caused by the protozoan parasites of the genus Trypanoso$m a$ and is transmitted mainly by biting tsetse flies of the genus Glossina. It is a major constraint to livestock production due to its negative effects on milk

* Author to whom correspondence is to be directed: E-mail: omotains@yahoo.com

Veterinary \& Livestock Studies Division, Nigerian Institute for Trypanosomiasis Research, PMB 03, Vom, Plateau State, Nigeria

Current address: Department of Veterinary Pathology, College of Veterinary Medicine, University of Agriculture, Abeokuta, PMB 2240, Abeokuta, Nigeria

2 Department of Veterinary Pathology, Faculty of Veterinary Medicine, University of Ibadan, Ibadan, Nigeria

Accepted for publication 14 April 2009-Editor production, mass gains, growth rates and reproduction. If left untreated it can lead to great economic losses in animals in terms of time and costs of treatment of animals, low productivity, infertility and mortality (Omamo \& d'leteren 2003).

Generally, trypanosome infections in sheep are characterized by progressive anaemia, loss of mass, oedema, lymphadenopathy, enlargement of the spleen, neurological and ocular lesions (lkede \& Losos 1975). Genital lesions characterized by scrotal oedema and non-suppurative orchitis with degeneration, atrophy, calcification and sclerosis of testicular tissues are seen in Trypanosoma bruceiand Trypanosoma vivax-infected rams (Ikede 1979; Anosa \& Isoun 1980). These changes are accompanied by low sperm counts and development of poor semen qualities (Akpavie, Ikede \& Egbunike 1987). 
Several reports are available on the haemopoietic responses in trypanosomosis. In ovine trypanosomosis, there is emaciation, splenomegaly, hepatomegaly, enlarged lymph nodes and generalized oedema. These lesions, which are characterized by a hyperactive mononuclear phagocytic system, are usually more prominent in the acute phase of the disease (Losos \& Ikede 1972; Anosa \& Isoun 1974; Anosa, Logan-Henfrey \& Shaw 1992).

The mechanisms adduced to some of these observations include lysis of blood cells (Anosa \& Kaneko 1983), haemodilution (Naylor 1971), haemorrhages (ILRAD 1984) and dyshaemopoiesis (Anosa et al. 1992; Omotainse \& Anosa 1992). Production of toxins by the trypanosomes could have some lethal effects on the marrow cells (Kaaya, Valli, Maxie \& Losos 1979; Lawson, Valli, Mills \& Forsberg 1980) which can result in reduced production or maturation of the erythroid cells. Likewise, phagocytosis of immature cells as demonstrated in the spleen of $T$. brucei-infected mice (Anosa \& Kaneko 1983, 1984) and in the bone marrow of $T$. vivax-infected calves (Anosa et al. 1992) can lead to the ineffective utilization of iron trapped in the macrophages in chronic trypanosomosis (Dargie, Murray, Grimshaw \& Mclntyre 1979). The capacity of monocytes to phagocytose red blood cells in vitro in $T$. congolense infection of goats was increased (Witola \& Lovelace 2001). These could contribute to the unsuccessful efforts of infected animals to increase the rate of erythropoiesis. To further understand the pathogenesis of anaemia in trypanosomosis, there is still the need to investigate the roles of some of the haemopoietic organs at various stages of infection involving different species of trypanosomes in different animal species.

The objective of this study, which was carried out using the Yankassa breed of sheep, was to investigate and compare the pathological changes in the lymph node, spleen, kidney and liver in acute and chronic ovine trypanosomosis, and to assess the possible roles of some of these organs in the pathogenesis of the anaemia in ovine trypanosomosis.

\section{MATERIALS AND METHODS}

\section{Experimental design}

The study was designed to produce disease of varying duration, ranging from acute to chronic in Yankassa rams. Fifty-two rams were used. Three groups of 14 rams each were infected with $T$. brucei, $T$. vivax or Trypanosoma congolense, respectively. Ten uninfected rams were kept as a control group.

\section{Parasites}

The parasites used were $T$. brucei (CT 70 isolated from cattle at Gboko in 1988), T. vivax (CT 128, isolated from cattle at Kafanchan in 1988) and T. congolense (GT 12, isolated from a goat at Gboko in 1988), and obtained from the liquid nitrogen bank of the Nigerian Institute for Trypanosomosis Research, Vom, Nigeria. These parasites are resistant to most of the common trypanocides at usual therapeutic doses.

\section{Infection}

The parasites were maintained in rams and harvested for the inoculation of the experimental animals. About $1 \times 10^{6}$ parasites were inoculated subcutaneously into each ram with the exception of those in the control group. Recommended curative but ineffective chemotherapy with a common trypanocide, diaminazene aceturate (Bereni ${ }^{\circledR}$, Hoechst, Frankfurt, Germany), at the recommended curative dose of $3.5 \mathrm{mg} / \mathrm{kg}$ for $T$. congolense and $T$. vivax was administered intramuscularly at between 4 and 6 weeks of infection as packed cell volume of the infected animals decreased, to allow for a chronic course of infection in each infected group of animals. Trypanosoma brucei-infected rams were similarly given $7.0 \mathrm{mg} / \mathrm{kg}$ body mass. The periods of infection before treatment, 5,6 and 5 weeks post infections (PI) with $T$. congolense, $T$. vivax and $T$. brucei, respectively, were regarded as the acute phase while the periods post treatment up to 19 weeks $\mathrm{PI}$ in $T$. congolense and 24 weeks $\mathrm{Pl}$ in both $T$. vivax and $T$. brucei infections were taken as chronic phase in this study.

\section{Pathological examination}

Post mortem examinations were carried out on the following numbers of animals in the different groups: the ten control animals, seven animals with acute $T$. congolense infection, six animals with chronic $T$. congolense infection, six animals with acute T. brucei infection, eight animals with chronic $T$. brucei infection, six animals with acute $T$. vivax infection and eight animals with chronic $T$. vivax infection. Apart from rams with acute $T$. brucei-infection where sudden deaths were recorded, infected animals were sacrificed when recumbent at the points of death in order to obtain fresh samples for examination. Samples of lymph nodes, spleen, kidney and liver were collected in formalinized saline solution for histopathology, and were processed and routinely stained with haematoxylin and eosin (H\&E) according to Drury \& Wallington (1967). The lesions 
were scored on a scale of low $(+)$, moderate $(++)$ and high (+++).

\section{Statistical analysis}

The mass of some of the organs were measured and their means compared using Student t-test in the SPSS statistical package at significant level of $P \leq 0.05$.

\section{RESULTS}

\section{Gross pathological observation}

Generally, in the three infections, there were cachexia and serous atrophy of fat, which were more pronounced in chronic infections.

There was enlargement of the prescapular and prefemoral lymph nodes, spleen, liver and kidneys (Table 1). Frequent urination was a prominent clini- cal sign observed in the three trypanosome infections from the second week of infection, particularly in the T. vivax infected animals. In both acute and chronic infections there were significant differences at various levels in the mass of the prefemoral and prescapular lymph nodes, spleens and livers (Table 1).

\section{Histopathological changes}

The lesions in the lymph nodes, spleen, kidney and liver of the rams in the three groups of infected rams are presented in Table 2. At the different phases of trypanosomal infections in this work, the lymph nodes and spleen demonstrated various degrees of severity of hyperplasia of the lymphoid follicles. The cortical and medullary regions of the lymph nodes showed congestion of the sinuses, proliferation of mononuclear cells, erythrophagocytosis and haemosiderosis.

TABLE 1 Mean mass (gm) of some organs of control and trypanosome infected Yankassa rams

\begin{tabular}{|lcc|l|l|l|l|}
\hline \multicolumn{2}{|l|}{ Prescapular lymph node } & & $\begin{array}{l}\text { Prefemoral } \\
\text { lymph node }\end{array}$ & Spleen & Liver & Kidney \\
\hline Control & $n=10$ & $6.8 \pm 1.8$ & $1.7 \pm 0.6$ & $56.8 \pm 33.8$ & $335 \pm 95.1$ & $65.7 \pm 9.6$ \\
Acute T. congolense & $n=7$ & $9.2 \pm 3.4^{\mathrm{c}}$ & $2.0 \pm 0.7^{\mathrm{c}}$ & $177.4 \pm 28.3^{\mathrm{b}}$ & $592.4 \pm 99.7^{\mathrm{b}}$ & $87.4 \pm 25.5^{\mathrm{a}}$ \\
Chronic T. congolense & $n=7$ & $10.4 \pm 3.8^{\mathrm{c}}$ & $3.2 \pm 1.1^{\mathrm{a}}$ & $107.9 \pm 23.9^{\mathrm{b}}$ & $498.1 \pm 88.5^{\mathrm{b}}$ & $75.4 \pm 4.1^{\mathrm{b}}$ \\
Acute T. vivax & $n=6$ & $8.0 \pm 1.3^{\mathrm{c}}$ & $1.9 \pm 0.4^{\mathrm{c}}$ & $79.3 \pm 29.7^{\mathrm{c}}$ & $335.7 \pm 4.7^{\mathrm{c}}$ & $70.7 \pm 20.5^{\mathrm{c}}$ \\
Chronic T. vivax & $n=8$ & $11.4 \pm 2.9^{\mathrm{a}}$ & $3.6 \pm 1.1^{\mathrm{a}}$ & $117.3 \pm 35.0^{\mathrm{b}}$ & $512.4 \pm 107.3^{\mathrm{b}}$ & $80.8 \pm 11.3^{\mathrm{b}}$ \\
Acute T. brucei & $n=6$ & $9.1 \pm 2.4^{\mathrm{c}}$ & $1.7 \pm 0.6^{\mathrm{c}}$ & $65.8 \pm 25.7^{\mathrm{c}}$ & $432.6 \pm 126.6^{\mathrm{c}}$ & $75.9 \pm 12.1^{\mathrm{c}}$ \\
Chronic $T$. brucei & $n=8$ & $9.2 \pm 3.3^{\mathrm{c}}$ & $2.2 \pm 0.8^{\mathrm{c}}$ & $78.03 \pm 2.8^{\mathrm{c}}$ & $380.9 \pm 133.2^{\mathrm{c}}$ & $71.0 \pm 12.9^{\mathrm{b}}$ \\
\hline
\end{tabular}

$n$ number of animals analysed

${ }^{a-c}$ level of significance between infected and control values: ${ }^{a} P<0.05 ;{ }^{b} P<0.01 ;{ }^{c} P>0.05$

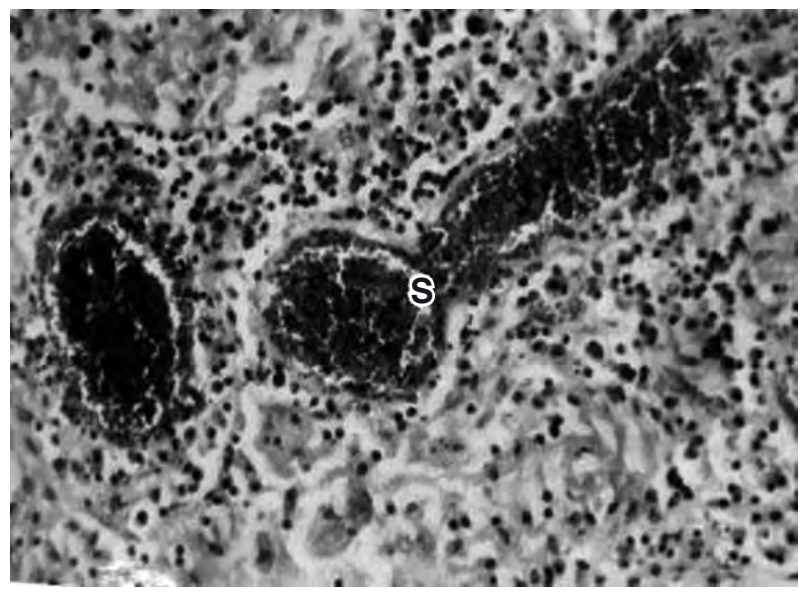

FIG. 1 Medullar region of a lymph node of a ram with acute $T$. brucei infection showing congested blood vessels (S).H \& $E, x 630$

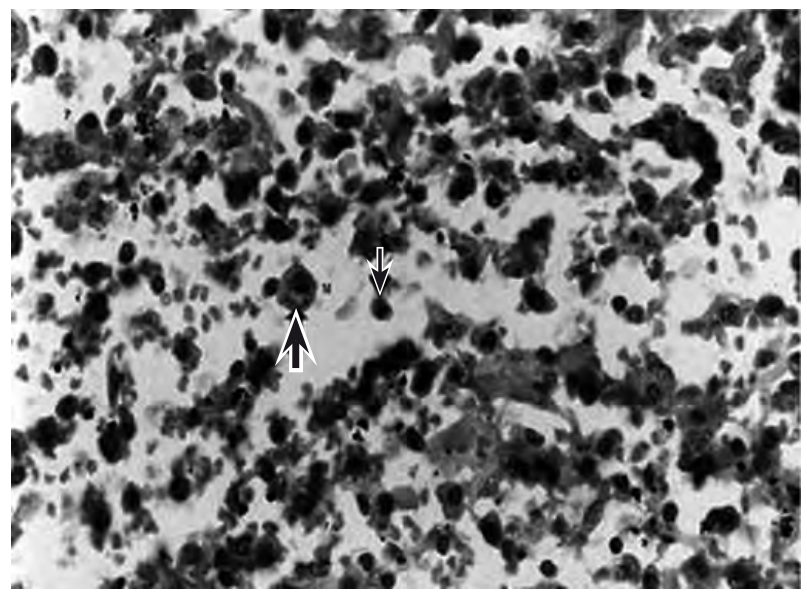

FIG. 2 Micrograph of the spleen of a ram with acute T. brucei infection showing depopulated red pulp, proliferation of macrophages (thick arrow) and plasma cells (thin arrow). $H \& E, x 630$ 


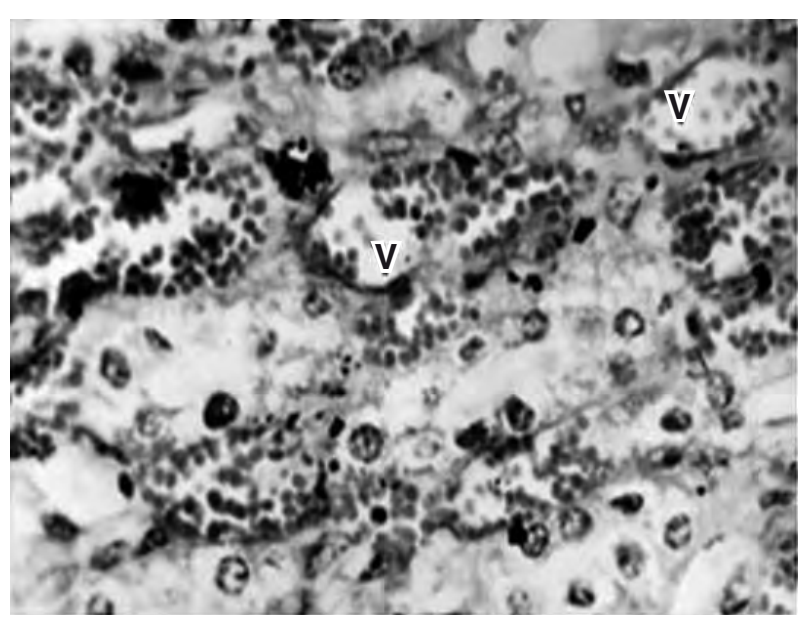

FIG. 3 Kidney of a ram with acute $T$. congolense infection showing diffuse congestion of the intertubular blood vessels (V). H \& E, x1200

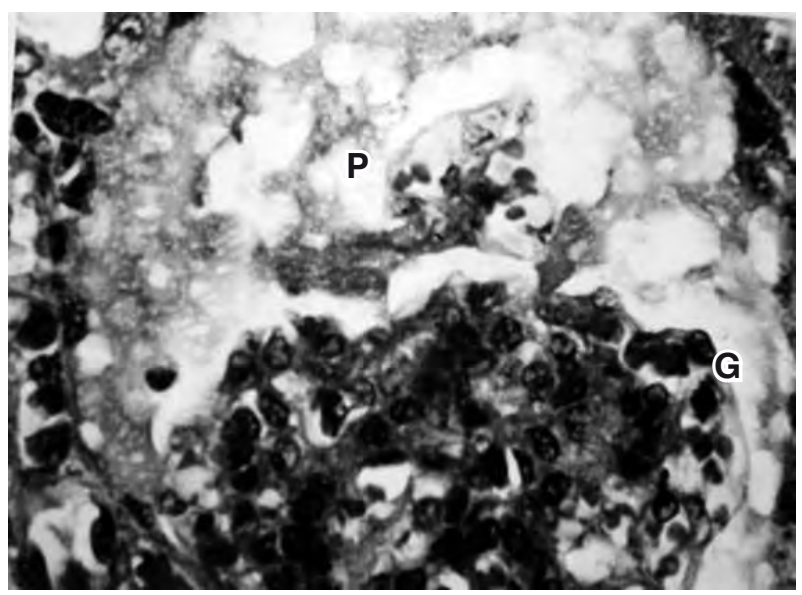

FIG. 5 The kidney of a ram with chronic $T$. vivax infection showing accumulation of protenous material $(P)$ in the Bowman's capsule of the glomerulus (G). H \& E, x1200

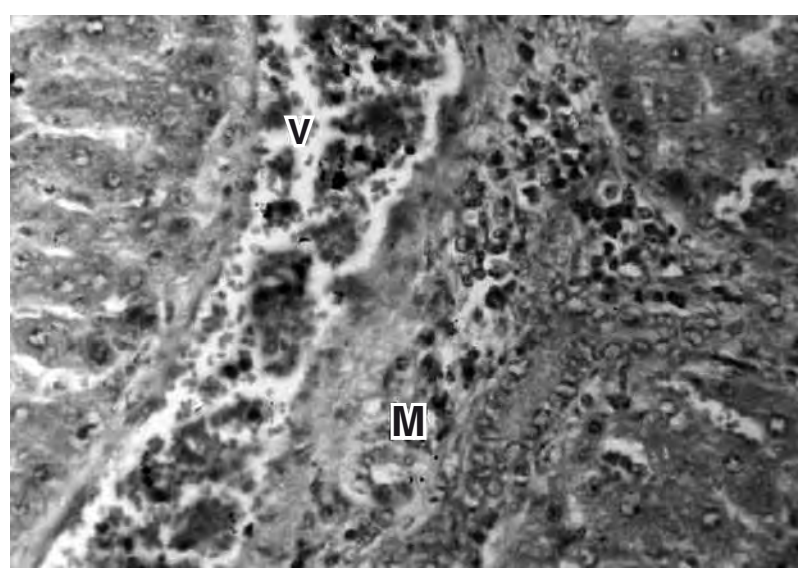

FIG. 7 Micrograph of the liver of a ram with chronic T. brucei infection showing congestion of a periportal vein $(\mathrm{V})$ and perivascular accumulation of lymphocytes and macrophages (M). H \& E, x1200

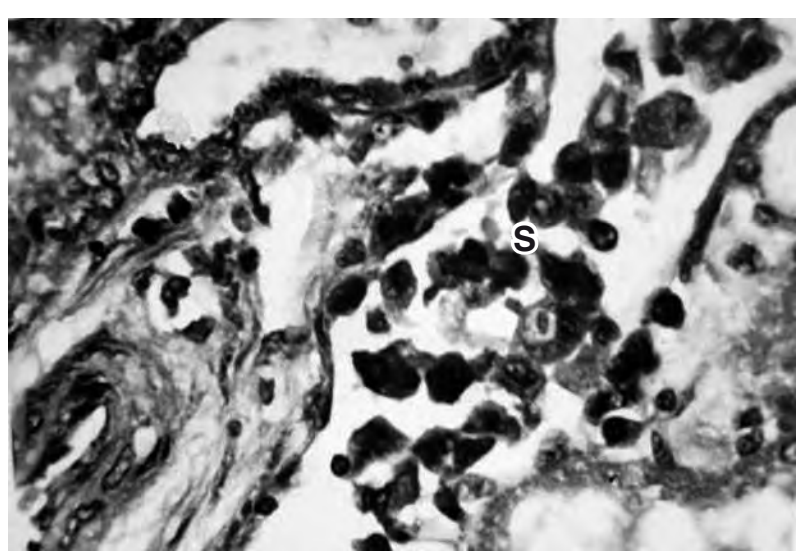

FIG. 4 Micrograph of the kidney of a ram with chronic T. congolense infection showing perivascular accumulation of macrophages and plasma cells (S). H \& E, x1200

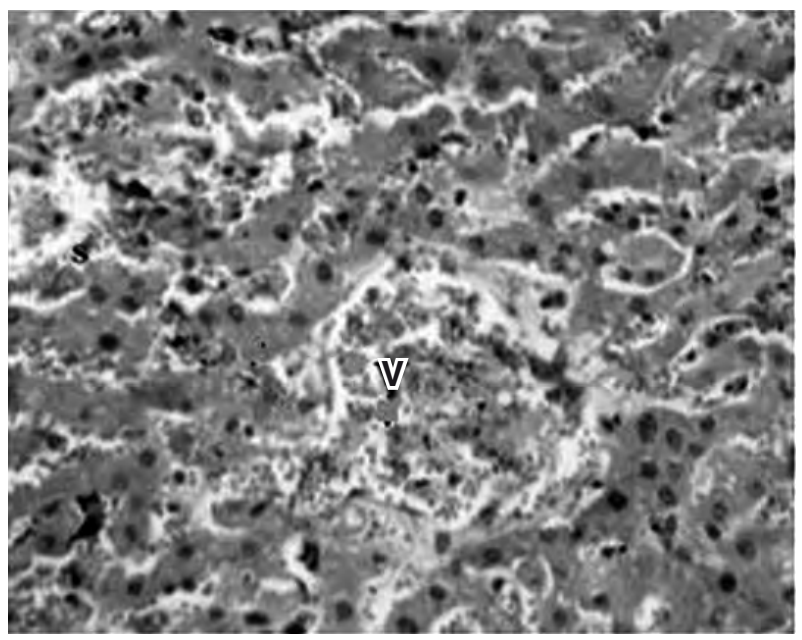

FIG. 6 Micrograph of the liver of a ram with acute T. congolense infection showing disorganized hepatic cords, diffusely congested sinuses (s) and central vein (V). H \& E, x1200

Similarly, the spleen of trypanosome-infected animals showed depopulated red pulp, proliferation of macrophages characterized by erythrophagocytosis and haemosiderosis as well as proliferation of plasma cells. There are differences in the extent of these reactions depending on the parasite species and stages of infection (Fig. 1 and 2).

The kidneys similarly demonstrated various degrees of congestion, perivascular and interstitial mononuclear cells infiltration, thickening of glomerular capsules, desquamation of tubular cells and protein casts in the tubules (Fig. 3-5).

The livers showed various degrees of vascular congestion, perivascular cuffing of mononuclear cells, hepatocellular degeneration and erythrophagocyto- 
TABLE 2 Summary of lesions in lymph nodes, spleen, liver and kidney in ovine trypanosomosis

\begin{tabular}{|c|c|c|c|c|c|c|}
\hline \multirow{2}{*}{ Organs/infections } & \multicolumn{2}{|c|}{ T. congolense } & \multicolumn{2}{|c|}{ T. vivax } & \multicolumn{2}{|c|}{ T. brucei } \\
\hline & Acute & Chronic & Acute & Chronic & Acute & Chronic \\
\hline \multicolumn{7}{|l|}{ Lymph node } \\
\hline $\begin{array}{l}\text { Erythrophagocytosis } \\
\text { Congestion } \\
\text { Enlargement of lymphoid follicles } \\
\text { Presence of plasma /Mott cells }\end{array}$ & $\begin{array}{l}+^{*} \\
++ \\
+ \\
+\end{array}$ & $\begin{array}{l}++ \\
+ \\
++ \\
++\end{array}$ & $\begin{array}{l}+++ \\
++ \\
++ \\
++\end{array}$ & $\begin{array}{l}+++ \\
++ \\
+++ \\
+++\end{array}$ & $\begin{array}{l}++ \\
++ \\
+ \\
++\end{array}$ & $\begin{array}{l}+++ \\
++ \\
++ \\
+++\end{array}$ \\
\hline \multicolumn{7}{|l|}{ Spleen } \\
\hline $\begin{array}{l}\text { Red pulp hyperplasia } \\
\text { Congestion of sinuses } \\
\text { Erythrophagocytosis } \\
\text { Haemosiderosis } \\
\text { Enlargement of the lymphoid follicles } \\
\text { Plasma cell proliferation }\end{array}$ & $\begin{array}{l}++ \\
++ \\
+ \\
++ \\
++ \\
+\end{array}$ & $\begin{array}{l}+ \\
+ \\
++ \\
+ \\
+ \\
++\end{array}$ & $\begin{array}{l}++ \\
++ \\
++ \\
++ \\
+ \\
+\end{array}$ & $\begin{array}{l}+ \\
+ \\
+ \\
++ \\
++ \\
++\end{array}$ & $\begin{array}{l}++ \\
+++ \\
+++ \\
+++ \\
++ \\
+\end{array}$ & $\begin{array}{l} \pm \\
+ \\
++ \\
+ \\
+ \\
+++\end{array}$ \\
\hline \multicolumn{7}{|l|}{ Kidney } \\
\hline $\begin{array}{l}\text { Vascular congestion } \\
\text { Peri-glomerular oedema } \\
\text { Glomerular degeneration/necrosis } \\
\text { Thickened Bowman's capsule } \\
\text { Tubular epithelial cell degeneration } \\
\text { Mononuclear cell infiltration }\end{array}$ & $\begin{array}{l}++ \\
+ \\
- \\
- \\
+ \\
-\end{array}$ & $\begin{array}{l}+ \\
- \\
+ \\
+ \\
++ \\
++\end{array}$ & $\begin{array}{l}++ \\
+ \\
- \\
- \\
+ \\
+\end{array}$ & $\begin{array}{l}+ \\
+ \\
+ \\
- \\
+ \\
++\end{array}$ & $\begin{array}{l}+ \\
+ \\
+ \\
- \\
+ \\
+\end{array}$ & $\begin{array}{l}+ \\
+ \\
- \\
- \\
+ \\
+\end{array}$ \\
\hline \multicolumn{7}{|l|}{ Liver } \\
\hline $\begin{array}{l}\text { Vascular congestion } \\
\text { Perivascular cuffing } \\
\text { Cellular degeneration } \\
\text { Erythrophagocytosis } \\
\text { Bile duct proliferation }\end{array}$ & $\begin{array}{l}+ \\
+ \\
+ \\
+ \\
-\end{array}$ & $\begin{array}{l}+ \\
++ \\
++ \\
++ \\
+\end{array}$ & $\begin{array}{l}+ \\
++ \\
++ \\
+ \\
-\end{array}$ & $\begin{array}{l}++ \\
+++ \\
++ \\
+ \\
-\end{array}$ & $\begin{array}{l}+ \\
++ \\
+ \\
+ \\
-\end{array}$ & $\begin{array}{l}+ \\
+++ \\
+++ \\
++ \\
++\end{array}$ \\
\hline $\begin{array}{r}\text { not noticeable } \\
+\quad \text { not significant }\end{array}$ & & $\begin{array}{l}+ \\
++ \\
+++\end{array}$ & derate & & & \\
\hline
\end{tabular}

sis according to the phase of the different trypanosomal infections (Table 2, Fig. 6 and 7).

\section{DISCUSSION}

The lesions in the lymph nodes of trypanosomeinfected animals included increased presence of macrophages with erythrophagocytosis, congestion, enlarged lymphoid nodules as well as increased plasma and Mott's cell populations. Apart from congestion, these lesions were more pronounced in the chronic than in the acute phase. Trypanosoma vivax and $T$. brucei infections showed more intense lesions than those in the rams infected with $T$. congolense. Perivascular mononuclear cell infiltration, mainly of lymphocytes, plasma cells and macrophages, in the liver was also a common feature in ovine trypanosomosis. These changes conform with those described earlier reports of $T$. vivax infection
(ILRAD 1984; Anosa et al. 1992) and in T. rhodesiense infection of humans (Robins-Browne, Schneider \& Metz 1975), and similarly were more intense in the chronic phase of the disease.

In this study, hyperplasia of the red pulp, congestion of the sinuses, enlargement of the lymphoid nodules, increased erythrophagocytosis, haemosiderosis and proliferation of plasma cells were the lesions seen in the spleen in acute $T$. congolense, $T$. vivax and $T$. brucei infections. The lesions were generally more pronounced in $T$. brucei infections than in $T$. congolense and $T$. vivax infections. The enlarged germinal centres of lymphoid nodules, especially during the acute phase of ovine trypanosomosis, are immunological reactions, presumably associated with the need for increased production of immunoglobulins. The presence of increased haemosiderosis is an indication of the major role the spleen plays in the destruction of red blood cells during try- 
panosomosis. This observation conforms to that of Anosa \& Isoun (1980) and Taylor \& Authie (2004). The presence of greater level of lesions such as erythrophagocytosis in $T$. brucei infections especially those in the acute phase of infection could contribute to the rapid development of anaemia despite the increased erythroid hyperplasia usually present in this phase of infection (Anosa et al. 1992). The mild enlargement of the lymphoid nodules of the spleen in the chronic $T$. congolense and $T$. brucei infections could be an indication of the declining role of humoral immunity in chronic trypanosomosis (Moulton 1986). This probably indicates exhaustion of the immune apparatus which would most probably lead to immunosuppression, thereby giving rise to the secondary bacterial infections reported by Kramer (1966) and Anosa \& Isoun (1983). The depopulation of lymphoid nodules was more pronounced in $T$. brucei infection than in the $T$. vivax and $T$. congolense infections. The immunosupression could be partly responsible for the sudden and higher mortality experienced with $T$. brucei infection as compared to others in this study.

Vascular congestion, disorganization of the hepatic cords, perivascular mononuclear cell infiltration, hepatocyte degeneration, hyperplasia of Kupffer cells and erythrophagocytosis were common lesions observed in the liver in acute form of ovine trypanosomosis in this study. These lesions were more pronounced in $T$. brucei infection than in $T$. congolense and $T$. vivax infections. Apart from the vascular congestion, these pathological changes were more pronounced in chronic $T$. brucei and $T$. vivax infections. The lesions associated with the various species of trypanosomes in this study were in good agreement with earlier reports on animal trypanosomosis (Losos \& Ikede 1972; Anosa \& Kaneko 1984; Taylor \& Authie 2004). This might have played a significant role in the inability of the animals to successfully recover from the anaemia experienced in trypanosomosis.

In summary, the lesions seen in the spleen, lymph nodes and the liver included the presence of activated macrophages, erythrophagocytosis and haemosiderosis indicating massive destruction of red blood cells in these organs, but these were more prominent in the spleen and lymph nodes. These changes confirm that these organs are the sites of red blood cell destruction in trypanosomosis.

The diffuse oedema, thickening of the glomerular capsule, tubular cell desquamation as well as accumulation of mononuclear cells in the intertubular septae and around the glomeruli of the kidneys in acute infections were more severe with chronicity. These lesions were more pronounced in $T$. vivax than in T. brucei and T. congolense infections, and might have been responsible for the constant urination which was most observed particularly in $T$. vivax-infected animals. Glomerulonephritis, characterized by thickened glomerular capsules, thickened intertubular and perivascular spaces by lymphocytes, plasma cells and macrophages, have been reported in T. brucei infection of rodents (Anosa \& Kaneko 1984), in T. gambiense infection of mice and in $T$. rhodesiense infection of monkeys (Nagle, Ward, Lindsey, Sadun, Johnson, Berkaw \& Hilderbrandt 1974). Damage to renal tissues, especially the juxta-glomerular cells (Jubb, Kennedy \& Perma 1985) can affect the production of erythropoietin, a hormone produced by the kidney to stimulate the bone marrow for erythropoiesis, thereby leading to inadequate stimulation of the bone marrow for the required increased production of red blood cells well above normal to reverse anaemia. Tubular damage can also lead to proteinuria, which may have been responsible for the constant urination in this study and can lead to death (Goodwin 1970). Therefore the lack of adequate erythrocytic response to the anaemia in ovine trypanosomosis may be attributed in part to the renal damage.

\section{CONCLUSION}

Trypanosoma congolense, T. vivax and T. brucei infections in Yankassa rams produced clinical disease with prominent lesions in several organs, with variations in severity depending on the parasite species and duration of infection. Pathological lesions including erythrophagocytosis, haemosiderosis and vascular congestion in the lymph nodes, spleen and liver as well as glomerular degeneration and necrosis of the kidneys, may have contributed to the clinical signs particularly the anaemia which is a consistent sign in animal trypanosomosis. Folicular hyperplasia of the lymphoid organs, vascular damage and tubular cell desquamation of the kidneys as well as cellular and vascular disruptions of the liver, coupled with the presence of erythrophagocytosis in these organs, further explain the possible cause of anaemia and other clinical signs and lesions in ovine trypanosomosis.

\section{ACKNOWLEDGEMENTS}

We thank the Director and the management of the Nigerian Institute for Trypanosomosis Research, Kaduna and the International Foundation for Sci- 
ence, as co-sponsors of this work. We deeply appreciate the technical assistance of $\mathrm{Mr}$ Christopher A. Ibitola for processing the tissues for histology.

\section{REFERENCES}

AKPAVIE, S.O., IKEDE, B.O. \& EGBUNIKE, G.N. 1987. Ejaculate characteristics of sheep infected with Trypanosoma brucei and $T$. vivax: changes caused by treatment with diaminazene aceturate. Research in Veterinary Science, 42:1-6.

ANOSA, V.O. \& ISOUN, T.T. 1974. Experimental T. vivax infection in sheep and goats: the relationship between the parasitaemia, growth rate and the anaemia. Journal of Nigerian Veterinary Medical Association, 3:102-108.

ANOSA, V.O. \& ISOUN, T.T. 1980. Further observations on the testicular pathology of $T$. vivax infection of sheep and goats. Research in Veterinary Science, 28:151-160.

ANOSA, V.O. \& KANEKO, J.J. 1983. Pathogenesis of T. brucei infection in deer mice Peromyscus maniculatus: Light and electron microscopic studies on erythrocyte changes and phagocytosis. American Journal of Veterinary Research, 44: 645-651.

ANOSA, V.O. \& KANEKO, J.J. 1984. Pathogenesis of T. brucei infection in deer mice Peromyscus maniculatus. Ultrastructural pathology of the spleen, liver, heart and kidney. Veterinary Pathology, 21:299-237.

ANOSA, V.O., LOGAN-HENFREY, L.L. \& SHAW, M.K. 1992. A light and electron microscopic study of changes in blood and bone marrow in acute haemorrhagic $T$. vivax infection in calves. Veterinary Pathology, 29:33-45.

DARGIE, J.D., MURRAY, P.K., MURRAY, M., GRIMSHAW, W.R.T. \& McINTYRE, W.I.M. 1979. Bovine trypanosomosis: the red cell kinetics of N'dama and Zebu cattle infected with T. congolense. Parasitology, 78:271-286.

DRURY, R.A.B. \& WALLINGTON, E.A. 1967. Carleton's histological techniques, $4^{\text {th }}$ ed. New York: Oxford University Press.

GOODWIN, L.G. 1970. The pathology of African trypanosomosis. Transactions of the Royal Society of Tropical Medicine and Hygiene, 64:797-817.

IKEDE, B.O. 1979. Genital lesions in experimental in chronic Trypanosoma congolense infection in rams. Research in Veterinary Science, 26:145-151.

ILRAD 1984. Anaemia in trypanosomiasis: haemorrhagic T. vivax may provide a clue. International Laboratory for Research on Animal Diseases 1983 Report, 2:1-3.

JUBB, K.V.F., KENNEDY, P.C. \& PERMA, M. 1985. Pathology of domestic animals, $3^{\text {rd }}$ ed. New York: Academic Press, 3:153159.
KAAYA, G.P., VALLI, V.E.O., MAXIE, M.G. \& LOSOS, G.J. 1979. Inhibition of bovine bone marrow granulocyte/macrophage colony formation in vitro by serum collected from cattle infected with $T$. vivax or $T$. congolense. Tropenmedizin und Parasitologie, 30:230-235.

KALU, A.U. \& EDEGHERE, H.U. 1985. Trypanosoma vivax in Nigerian goats: economic effects of the infection. Nigerian Journal Animal Production, 2:12.

KRAMER, J.W. 1966. Incidence of trypanosomosis in the West African Dwarf sheep and goats in Nsukka, Eastern Nigeria. Bulletin of Epizootic Diseases of Africa, 14:423-428.

LAWSON, B.M., VALLI, V.E.O., MILLS, J.N. \& FORSBERG, C.M. 1980. The quantitation of $T$. congolense in calves. IV. In vitro culture of myeloid and erythroid marrow cells. Tropenmedizin und Parasitologie, 31:425-434.

LOSOS, G.J. \& IKEDE, B.O. 1972. Review of pathology of disease in domestic and laboratory animals caused by $T$. vivax, $T$. brucei, $T$. rhodesiense and $T$. gambiense. Veterinary Pathology, Supplement 9:1-17.

MOULTON, J.E. 1986. Structural and functional changes in the lymphoid organs of cattle infected with $T$. congolense. Tropical Veterinarian, 4:97-106.

NAGLE, R.B., WARD, P.A., LINDSEY, H.B., SADUN, E.H., JOHNSON, J., BERKAW, K.E. \& HILDERBRANDT, P.K. 1974. Experimental infections with African trypanosomosis. IV. Glomerulonephritis involving the alternate pathway of complement activation. American Journal of Tropical Medicine and Hygiene, 23:15-26.

NAYLOR, D.C. 1971. The haematology and histopathology of $T$. congolense infection in cattle. Part III, Discussion and conclusion. Tropical Animal Health and Production, 3:203-207.

OMAMO, S.W. \& D'IETEREN, G.D.M. 2003. Managing animal trypanosomosis in Africa: Issues and options. Revue Scientifique et Technique-Office International des Epizooties, 22:989-1002.

OMOTAINSE, S.O. \& ANOSA, V.O. 1992. Erythrocyte response to Trypanosoma brucei in experimentally infected dogs. Revue d'Elevage et de Medecine Veterinaire des Pays Tropicaux, 45:279-283.

ROBINS-BROWNE, R., SCHNEIDER, B.J. \& METZ, J. 1975. Thrombocytopenia in trypanosomosis. American Journal of Tropical Hygiene, 24:226-231.

TAYLOR, K. \& AUTHIE, M-L. 2004. Pathogenesis of animal trypanosomiasis, in The trypanosomoses, edited by I. Maudlin, P.H. Holmes \& M.A. Miles. Oxfordshire: CABI Publishing. 331-353.

WITOLA, W.H. \& LOVELACE, C.E. 2001. Demonstration of erythrophagocytosis in Trypanosoma congolense-infected goats. Veterinary Parasitology, 96:115-126. 